\title{
Problemas de agencia en la educación básica en México: un diagnóstico institucional
}

\author{
Agency problems in basic education in Mexico: \\ an institutional diagnosis \\ Reynaldo Angulo-Cázares / reynaldo.angulo.cazares@uabc.edu.mx
https://orcid.org/0000-0002-9063-1425
Universidad Autónoma de Baja California, México
}

\begin{abstract}
Given the centrality that the educational reforms of Pacto por México give to the rules of the game -vis a vis teacher behavior-, this paper examines its preexisting institutional design. The starting point was the existing claims that such design created agency problems. Our purpose was to prove the configuration of a specific type of agency problem: organizational moral hazard. We deconstructed normativity with the Institutional Grammar Tool (IGT), proposed by Crawford and Ostrom (1995). IGT allows to systematically identify -if any- the rules present in policy documents, unveiling the genetic code of policies that configure arenas where individuals display their interactions. We found that the way control management at schools is structured in relation to the application of sanctions to teachers constitutes a moral hazard situation given its assumptions.
\end{abstract}

Key words: Pacto por México, basic education, teacher behavior, moral hazard, Institutional Grammar Tool (IGT).

Resumen: Dada la centralidad que la reforma educativa del Pacto por México pone a las reglas del juego - vis a vis conducta docente-, este artículo examina el diseño institucional que le precede. Se problematizaron afirmaciones como que el diseño previo creaba problemas de agencia. El objetivo fue demostrar la configuración de un tipo específico de problema de agencia: el riesgo moral organizacional. Se deconstruyó la normatividad con la Herramienta de la Gramática Institucional (IGT), de Crawford y Ostrom (1995). El IGT permite identificar sistemáticamente las reglas presentes -si las hubiere- en documentos de políticas, develando el código genético de las políticas que configuran arenas, lugar donde los individuos interactúan. Se encontró que la forma como se estructura el control administrativo en los planteles en relación con la aplicación de sanciones a maestros constituye una situación de riesgo moral dado sus supuestos.

Palabras clave: Pacto por México, educación básica, conducta docente, riesgo moral, Herramienta de la Gramática Institucional (IGT). 


\section{Introducción}

Las organizaciones, según North (1993), al igual que las interacciones de los individuos, son moldeadas por las reglas del juego. Estas últimas son oportunidades y restricciones que, mediante incentivos, orientan la conducta de los individuos. A este proceso configurativo se alude cuando se afirma, a tente bonete, que las reglas del juego importan.

Los trabajos de Ostrom dan un giro a esta tesis, al acentuar el papel del lenguaje en las reglas (Kiser y Ostrom, 1982; Siddiki et al., 2011; Crawford y Ostrom, 1995; Ostrom, 2005). Mediante el lenguaje, sostiene la autora, las reglas tienen el potencial para moldear profundamente la conducta individual y el contexto organizacional donde se da la interacción. De ahí que para lograr una mejor comprensión de la conducta y del desempeño de los actores habría que revisar el lenguaje de las reglas del juego y cómo el mismo lenguaje configura a las organizaciones.

La reforma al marco normativo de la educación básica en México, efectuada en 2013, sigue una línea programática similar a la anterior. Bracho y Zorrilla (2015) señalan que con dicha reforma se busca modificar conductas de los actores del sistema educativo e impulsar nuevos patrones de conducción e interacción inter e intraorganizacionales, lo cual se lograría mediante un nuevo andamiaje de reglas. Esto último es la hipótesis de intervención ${ }^{1}$ de la reforma, la cual está clara. No obstante, en cuanto a la hipótesis de causalidad, ${ }^{2}$ hay menor claridad. Sólo se insinúa que el problema es conductual y que el andamiaje de reglas previo es responsable de ello.

\section{El problema: la hipótesis de causalidad}

En sus reflexiones, Jaime Torres-Bodet (TB), titular de la Secretaría de Educación Pública (SEP) en dos ocasiones (1943-1946 y 1958-1964), aporta elementos concretos que permiten formular una hipótesis de causalidad. No sólo identifica la pieza normativa que contiene el viejo andamiaje, sino que indica patrones organizacionales y conductuales que se derivan de ella. TB presenció el ensamblaje de los arreglos institucionales para la educación básica vigentes hasta hoy.

1 La hipótesis de intervención son "los métodos de acción gubernamental que influirán las decisiones y actividades de los grupos destinatarios designados" (Knoepfel et al., 2007: 59).

2 La hipótesis de causalidad es la "respuesta política a la pregunta de qué o quién... [es] capaz de hacer cambios para que el problema colectivo sea resuelto” (Knoepfel et al., 2007: 57). 
Por arreglo institucional se entiende un conjunto de reglas o acuerdos -formales e informales- que gobiernan las actividades de un grupo específico de personas, persiguiendo ciertos objetivos (Davis y North, 1971). Loyo-Brambila (2010) señala que una de las piezas normativas estructurantes de más peso configurativo para el sistema educativo provino del entorno. Esta pieza normativa era el Estatuto Jurídico para los Trabajadores de los Poderes de la Unión, propuesto por el presidente Lázaro Cárdenas (1934-1940) y ratificado en 1941 por el presidente Manuel Ávila Camacho (1940-946).

Según TB, el Estatuto creaba dos problemas en relación con el personal docente. El primero era perceptual-conductual. Con el Estatuto ya no se tenía "más puertas normales de escape que la renuncia, el retiro o la defunción" (Torres-Bodet, 1994: 64), lo cual afectaba creencias y conductas de maestros. "El Estatuto les hizo creer que bastaba ingresar -como fuera- y, después, durar” (Torres-Bodet, 1994: 65). Lo más grave de esta creencia es que conducía al "estatismo", término acuñado por el mismo TB para referirse al relajamiento laboral. Aclara: "Y [...] empleo la palabra 'estatismo' [...] en la acepción de inmovilidad en lo estático" (Torres-Bodet, 1994: 64-65). Con el Estatuto, pues, se afectaba no sólo las creencias de los maestros, sino su desempeño o esfuerzo en las labores cotidianas.

El otro problema era de control administrativo. Comentaba: "En 1943 imaginé $[\ldots]$ que la $[\ldots]$ unidad sindical [...] contribuiría a mejorar la federalización (centralización)" (Torres-Bodet, 1994: 243). No todo salió acorde al plan. A su regreso, tres lustros más tarde, ${ }^{3}$ se "daba cuenta de que, desde el punto de vista administrativo, la federalización no era recomendable [al igual que] la unificación sindical no parecía favorecer de manera muy positiva a la calidad del trabajo docente de los maestros" (Torres-Bodet, 1994: 243).

El problema era que la SEP (Torres-Bodet, 1994: 243) había

[...] perdido contacto con la realidad de millares de escuelas sostenidas por el gobierno.

Nuestros informantes directos eran inspectores que, como socios activos del sindicato, encubrían a tiempo las faltas y las ausencias de los maestros, pues no ignoraban que les sería, a la larga, más provechosa que la estimación de sus superiores.

Los alcances teórico-conceptuales de este problema se analizan más adelante. Algunos estudios han teorizado el vínculo entre arreglos laborales y conducta docente. Es el caso de los estudios de Ezpeleta (1992, 1997, 2004a; Ezpeleta y Furlán, 1992; Ezpeleta y Weiss, 1996). Su propuesta es una clasificación de normatividades, una de las más fructíferas en la investigación en México (Tapia-Uribe, 2004). Ezpeleta define a las escuelas públicas como "configuraciones complejas, reguladas por normatividades múltiples

3 Se refiere a su segundo periodo frente a la SEP (1958-1964). 
y específicas -escritas y no escritas-, no siempre coherentes" (Ezpeleta, 2004b: 168).

Estas normatividades son la laboral, la administrativa y la pedagógica. Las dos primeras contienen los mecanismos de control más definidos para la conducta y acción pedagógica (Ezpeleta, 1990 y 2004b). Aunque Ezpeleta también señala que "las reglas laborales [...] parecen constituir, en los planteles, el suporte del poder burocrático" (Ezpeleta, 1990: 22). A estas les llama "bases duras" o "parámetros fuertes".

En los planteles los docentes se enfrentan a un doble sistema de referencias -el sindical y el administrativo-, lo cual se traduce en márgenes de tolerancia diferenciados (Ezpeleta, 1997) o precariedad institucional (Ezpeleta y Weiss, 1994). Y es que, en la práctica, el rol del director se reduce a representante formal ante la comunidad y burocracia educativas; "frente a los maestros [...] carece de autoridad formal y técnica” (Ezpeleta y Weiss, 1996: 59). El supervisor, puesto superior inmediato, sólo realiza actividades operativas (recopilar estadísticas, procesar documentos, etcétera).

Los supervisores no tienen capacidad para resolver conflictos intraescolares (Gómez- Nashiki, 2010). Tratándose del manejo del personal escolar, otra función a su cargo, "se da paso al interés sindical como instancia que hegemoniza las reglas" (Ezpeleta y Weiss, 1996: 60). Esto es así porque deben el "cargo al aval del sindicato y continúan con su pertenencia gracias a él" (Ezpeleta y Weiss, 1996: 60). Esto equivale a la pérdida de control referida por TB.

Los efectos configurativos de estos arreglos permean la esfera organizacional, incidiendo en la conducta del personal escolar. Gómez-Nashiki (2010: 799) reporta que, en el plantel escolar, el poder procede, más que de la autoridad formal, "de las alianzas dominantes que se gestan y se establecen en la institución”. Las alianzas se forman entre grupos de maestros con la participación o aval del representante sindical. Ezpeleta y Weiss (1994: 80) han señalado que hay maestros que, con sus conductas, tensan "al máximo la tolerancia institucional".

Una de esas conductas es el ausentismo, si bien no se limita a ello. Una “combinación de reglamentos y usos consagrados [...] proveen de numerosas razones institucionales legitimadoras del ausentismo" (Ezpeleta y Weiss, 1994: 81) o conductas similares. La reacción sería, como lo indicaba TB, el encubrimiento por parte de la autoridad del plantel, respaldándose en estos reglamentos y usos mencionados.

Tanto estos hallazgos como las observaciones de TB pueden ser integrados parcialmente por la Teoría de la Agencia (TA). Para esta, los problemas 
señalados por TB son problemas de agencia. La TA asume que el agente, al ser reclutado por el principal, hará una representación dudosa de sus habilidades, intereses y preferencias. El principal no puede verificar con certeza tal representación (Jensen y Meckling, 1976; Ferris, 1992; Moe, 2005; Shapiro, 2005). A esto se le llama asimetría de información.

Dicha dificultad atraerá un número desproporcionado de solicitantes de baja calidad (Moe, 1984). A la conducta del agente se le llama oportunismo ex-ante (Lane y Svante, 2000; Lane, 2008). Al final, se corre el riesgo de hacer una selección adversa del agente (Rauchhaus, 2009; Shapiro, 2005); aunque los problemas no terminan allí.

Los problemas para el principal continúan después de que los agentes son contratados o de que ingresan a la organización. En esta fase persiste la asimetría de información al dificultársele al principal conocer la conducta/esfuerzo del agente -contratado por el principal para llevar a cabo una actividad que no puede realizar-. Simplemente, el agente tiene más información (Gibson et al., 2005; Levaćič, 2009; Lane, 2008; Ferris, 1992; Shapiro, 2005). A esto se le llama acción oculta. Monitorear directamente las acciones del agente, además, es costoso. Surge la necesidad de contratar a un supervisor (un agente que sea el principal del agente, el maestro en este caso) para que lo haga. Esta nueva relación, por cierto, no está desprovista de los problemas de agencia mencionados. Puede empeorarlos.

Las relaciones agente-principal (A-P) implícitas en las observaciones de TB van más allá de dicha díada. En ellas aparece un tercer elemento, el cual es clave en la pérdida de control (acción oculta) y de las conductas resultantes. Esta figura es el inspector (supervisor). Tirole (1986) desarrolló un modelo en el cual el rol del supervisor agrega mayor complejidad a la relación A-P.

La figura del supervisor introduce la posibilidad de colusión con el agente vis a vis el principal. El efecto más relevante de esta colusión es la manipulación de información, la cual puede darse de tres formas: ocultamiento o distorsión de evidencia existente, o la no creación de evidencia sobre la conducta/esfuerzo del agente. La colusión es particularmente viable cuando la información que se tiene que reportar es difícil de verificar. Está claro que al principal no le conviene la colusión.

Sin importar los motivos de la acción oculta, el agente-maestro se encuentra en situación de riesgo moral (Levaćič, 2009; Rauchhaus, 2009; Shapiro, 2005; Lane, 2008; Casson, 2007; Ferris, 1992; Arnott y Stiglitz, 1991). Es situación de riesgo moral porque lo único que regula la conducta del agente es su código moral. Pero este no es el único mecanismo que desemboca en dicha situación. Hay otro vinculado al problema de motivación 
señalado por TB. Este mecanismo es el contrato que formaliza la relación agente-principal.

El contrato puede diseñarse de tal forma que "una parte contratante cambie su conducta después de firmar(lo)”4 (Lane, 2008: 5). Arnott y Stiglitz (1991) explican que "el riesgo moral ocasiona que individuos plenamente asegurados desplieguen poco esfuerzo"s (Arnott y Stiglitz, 1991: 180). El contrato, al otorgar seguridad laboral, crea una condición de riesgo moral, el cual puede derivar en relajamiento laboral, como señalaba TB. Esto recibe el nombre de oportunismo ex post (Lane y Svante, 2000; Lane, 2008).

Aquí conviene distinguir las dos condiciones en que se da la asimetría de información: la a-institucional y la institucional. La TA refiere a la primera, pues la ventaja en la información atribuible al agente obedece al contacto directo que este tiene con su realidad diaria, ya sea personal $u$ organizacional. La ventaja es cognitiva. El contrato (u arreglo) vendría a ser la respuesta a los problemas de agencia derivados de la delegación que hace el principal al agente.

En cambio, la asimetría referida por TB (y la perspectiva de las "bases duras") era institucional, pues atribuía los mismos efectos conductuales al Estatuto. La SEP no podía obtener información, debido a la colusión entre supervisores con los agentes operativos (directores y maestros), lo cual, sugiere TB, está vinculado al mismo Estatuto por la vía sindical y laboral.

Señalar que los arreglos derivados de la normatividad fundacional estructuraban dinámicas organizacionales y conductuales, es una aportación necesaria pero no suficiente. Lo es porque ahonda en los efectos configurativos del diseño dejando pendiente sus particularidades. Adopta en todo caso una visión de "caja negra". Las reformas recientes tendrían mayor impacto si se indican los componentes institucionales específicos detrás de las conductas referidas.

El objetivo de la presente investigación es corroborar la configuración de los problemas de agencia señalados por TB. Esto lo hacemos de-construyendo el lenguaje de la normatividad referida. Queremos mostrar cómo se forma la coalición de la tríada director-supervisor-docente, situación de riesgo moral en la que convergen la ruta de la estabilidad laboral y la colusión. Este trabajo pretende ser, en cierto modo, la explicitación de un diagnóstico faltante de las reformas.

4 La traducción es nuestra.

5 La traducción es nuestra. 


\section{Método}

\section{Selección del material}

El Estatuto estuvo vigente entre 1941 y 1963. En este último año fue sustituido por la "Ley Federal de los Trabajadores al Servicio del Estado, Reglamentaria del Apartado B del Artículo 123 Constitucional” (LFTSE). En 1960, se había reformado el artículo 123 constitucional, agregándosele el Apartado B, brindándole sustento legal a las relaciones laborales con los empleados al servicio del Estado.

Al sustituir al Estatuto, la LFTSE vino a reglamentar el Apartado B, volviéndose de observancia general para todos los empleados del gobierno federal, incluidos los maestros de educación básica. Si bien cada entidad federativa puede crear su propia legislación en la materia, asumimos que el Estatuto-LFTSE ha sido referente para ello. Igualmente, asumimos que los arreglos plasmados en la LFTSE han sido referente para las normas de los estados y que, para efectos de análisis, en esencia son los mismos arreglos.

Dado que el Estatuto regulaba las relaciones laborales de los empleados del gobierno federal, en 1946 se decretó el "Reglamento de las Condiciones Generales de Trabajo del Personal de la Secretaría de Educación Pública” (en adelante Reglamento), completando el marco normativo para empleados de la SEP. A pesar de que el Estatuto ya no está vigente, el Reglamento ha sobrevivido a los vaivenes de las reformas efectuadas hasta hoy.

En este trabajo, por lo tanto, se analizan la LFTSE y el Reglamento. Ambas piezas normativas estructuran diversos asuntos de las relaciones laborales entre los empleados-agentes del gobierno federal y este. De ahí que sólo fueron seleccionados los artículos que estructuran las posibilidades de salida o, en el lenguaje de TB, las "puertas de escape". De esta manera, de la LFTSE se examinaron los capítulos VI y VII del título segundo. En estos se establecen los procedimientos que se siguen para la "suspensión" y el "cese". Del Reglamento se analizó el capítulo XII, el cual trata sobre "infracciones” y "recompensas".

\section{Recolección y análisis de datos}

La recolección de datos para la investigación reportada en este artículo se llevó a cabo a través del análisis de contenido de la LFTSE y del Reglamento. Para ello nos apoyamos en la IGT propuesta por Crawford y Ostrom (1995). Comúnmente, la IGT se usa para de-construir instituciones 
formales (regulaciones, leyes, etc.), las cuales se operacionalizan mediante enunciados institucionales. Un enunciado institucional es "una restricción u oportunidad lingüística compartida que prescribe, permite o sugiere a los actores, individuales y corporativos, acciones o resultados" 6 (Crawford y Ostrom, 1995: 583). Un enunciado institucional se forma de componentes, las unidades gramáticas básicas (véase Cuadro 1). ${ }^{7}$ De esta manera, los arreglos institucionales se reducen a su expresión lingüística a través de enunciados (Crawford y Ostrom, 1995; Basurto et al., 2009).

Originalmente, Crawford y Ostrom (1995) asignaron a los enunciados institucionales los componentes gramaticales: Atributo (A), Deóntico (D), Condición (C), propósIto (I) y De lo Contrario (Or else) (O). Posteriormente, Basurto et al. (2009) y Siddiki et al. (2011) agregaron el componente "objeto" (B). En el Cuadro 1 se definen y ejemplifican estos componentes. De todos, el deóntico requiere algunas precisiones. Este operador especifica si una acción es requerida ("tiene que" o "debe"), permitida ("puede") o prohibida ("no debe", "no puede").

No siempre tiene que estar redactado de manera explícita, sino también puede estar de forma implícita (Basurto et al., 2009). Aún más, puede estar ubicado fuera del enunciado; puede estar colocado al inicio de un párrafo, sección u otra parte. El deóntico puede variar por la fuerza prescriptiva (Crawford y Ostrom, 1995). Por ejemplo, no tiene la misma fuerza prescriptiva "debe" y "tiene que". Estas diferencias son claves al momento de delinear la fuerza de un enunciado institucional.

$\mathrm{Al}$ analizarse la normatividad se atiende la forma en que la gramática institucional estructura las diversas situaciones, tomando en cuenta la redacción de todos los componentes. Todo enunciado contiene, como mínimo, componentes ABIC (atributo, objeto, propósito y condiciones). Cuando es el caso, se está frente a una estrategia, la cual impone condiciones para la acción con mínima fuerza prescriptiva. En cambio, cuando el enunciado incluye hasta un deóntico se está ante una norma ABDIC, con fuerza prescriptiva. Al contar con un "De lo Contrario" (Or else) se está ante una regla ABDICO, con un nivel de fuerza prescriptiva mayor a la norma. Ahora, las estrategias son "planes regularizados que los individuos realizan dentro de (una) estructura de incentivos" ${ }^{8}$ (Ostrom, 2007: 23).

6 La traducción es nuestra.

7 Todos los cuadros se encuentran en el Anexo, al final del presente artículo (Nota del editor).

8 La traducción es nuestra. 
El grado de información que poseen los actores sobre la estructura de la situación en que interactúan es clave para definir la estrategia a seguir. La interacción cotidiana de los maestros a nivel operativo les permite obtener información detallada y conocimiento profundo de las posibilidades de acción; es decir, sobre las estrategias a emprender.

Las normas son prescripciones de acciones o resultados enfocados a recompensas no-materiales. Las normas constriñen. Culturalmente inducidas -más que sancionadas por alguna Constitución-, su transformación es lenta y sutil. Aunque pueden emerger del interior del individuo, la mayoría se adquieren en el contexto de una comunidad con la que el individuo interactúa con frecuencia (Ostrom y Basurto, 2010).

Las reglas, en caso de acciones prohibidas, contienen una sanción adicional y son observadas por un monitor. Para que las reglas sean tales, cualquier situación particular debe estar vinculada a una instancia creadora de reglas y debe existir algún tipo de monitoreo y sanción (Basurto et al., 2009; Ostrom y Basurto, 2010; Crawford y Ostrom, 1995). Las reglas pueden ser modificadas discretamente de un día para otro. El ejemplo del Cuadro 1 es una regla porque incluye el operador "De lo Contrario".

Resumiendo, las combinaciones de enunciados institucionales estructuran situaciones de acción en el sistema educativo; es decir, fijan las acciones o resultados posibles, sugeridos u obligatorios a los actores. Con este marco se analiza la aplicación de sanciones o castigos a maestros, conducentes al cese ("puertas normales de escape"). Por lo tanto, en este trabajo se revisa de manera minuciosa e iterativa cada enunciado institucional que vincule a esta situación de acción. Para determinar la fuerza de todos los enunciados se atiende si estos son: estrategias, normas o reglas. Pero también se atienden otros componentes (atributo, propósito y objeto) para determinar el grado de contribución a las situaciones de acción.

\section{Resultados}

Esta sección se divide en dos partes. En la primera se analizan las infracciones contempladas en el Reglamento; es decir, sanciones que pueden conducir al cese. Este es un "carril lento", el cual conduce a la salida. Como en toda organización, la aplicación de sanciones supone autonomía del principal (directores de plantel) en el ejercicio de la autoridad; en este caso la aplicación de sanciones. El Reglamento regula una diversidad de conductas de maestros (puntualidad, esfuerzo, asistencia, etcétera), esenciales para, entre otras cosas, el orden y el funcionamiento del plantel escolar. La aplicación 
de las sanciones descansa en el director (en el "atributo", según el lenguaje de la IGT). Pero, como ya se abordó con anterioridad, este supuesto resultaba problemático por la dependencia del personal operativo hacia el sindicato para su promoción y obtención de otros beneficios.

En la segunda parte se analizan las secciones de la LFTSE que contemplan sanciones severas, como el cese. Este es un "carril rápido" que lleva a la salida. Para este desenlace se parte del supuesto previo y, además, se le agrega una zona discrecional.

\section{Carril lento}

Aquí se analiza el contenido del capítulo XIV “De las Infracciones y Recompensas” del Reglamento. El contenido del capítulo XII equivale a una parte de los contenidos de la LFTSE, razón por la cual se examinan en su conjunto más adelante. Los artículos 70-75 plasmados en el capítulo XIV son la “conceptualización” del capítulo. El art. 70 señala que: "En todos los casos de infracciones y recompensas no previstas por el Estatuto se aplicarán las prevenciones del presente capítulo". La LFTSE, pues, tiene preponderancia. $\mathrm{El}$ art. 71 define las infracciones que un trabajador de base puede recibir, presentándose un continuo progresivo que va desde una infracción leve a una grave: se empieza con amonestaciones y extrañamientos verbales y escritos; le siguen notas malas en la hoja de servicio; pérdida de derecho para percibir sueldos; suspensión de empleo, cargo o comisión y, finalmente, el cese del nombramiento, la máxima infracción.

1. El art. 72 señala que el jefe de dependencia hará extrañamientos por escrito, con copia al Departamento de Personal y a la Comisión Nacional de Escalafón. Para el caso que nos ocupa, el jefe de la dependencia es el director del plantel escolar, jefe inmediato del docente. El art. 73 estipula que tres extrañamientos equivalen a nota mala. Esta, a su vez, la otorga el Departamento de Personal, órgano administrativo central alejado de las interacciones de campo (véase Cuadro 2). Pero, como lo estipula el art. 74, han de presentarse dos condiciones.

La condición C1 refiere a la acumulación de los tres extrañamientos referidos en el art. 73. La actuación del Departamento de Personal A1 se activa una vez recibida la notificación de los tres extrañamientos. La otra condición C2, acumulativa, es que la dirección del plantel A2 lo solicite habida justificación para ello. El director del plantel no sólo tiene que emitir extrañamientos sino solicitar la mala mota. 
Este supuesto ha de ser visto a través de la afinidad de intereses y preferencias que estructura el mismo Reglamento. El art. 11 del Reglamento -y la fracción III del art. 15 de la LFTSE- señala que los contratos que la Secretaría puede celebrar con sus trabajadores pueden ser nombramiento definitivo, interino, por tiempo fijo o por obra determinada. El art. $6^{\circ}$ de la LFTSE define a los trabajadores de base como inamovibles. Aquí tomamos a la inamovilidad y a la plaza base como sinónimos.

Los artículos 5, 6, 7 y 8 del Reglamento son clave. El art. 5 estipula que "los trabajadores de base de la SEP se subdividirán en tres grandes grupos: docentes, técnicos y administrativos". El art. 6 define quiénes son maestros, y el art. 7 define quién es el personal técnico. A su vez, el art. 8 adopta un enfoque definitorio por defecto: "Se considera como administrativo al personal que no desempeñe funciones (docentes y técnicas)". Todo el personal escolar operativo, con roles de agentes y principales, es de base.

Ahora, la inamovilidad laboral no se otorga solamente a los puestos más bajos en la jerarquía escolar (por ejemplo, maestros). También se otorga a los puestos que se encargan de supervisar, controlar y monitorear la conducta de dicho personal. Aquí adquiere relevancia lo estipulado por Tirole (1986), sobre el rol del supervisor. Calvo-Pontón et al. (2002: 204) explican que "el cargo de jefe de sector es el último puesto de base al que un maestro puede llegar por ascenso escalafonario". Para participar en ascensos, es requisito ser empleado de base (art. 48, LFTSE). Se ha señalado (Street, 1983; Ornelas, 2002 y 2008), además, que los niveles medios y altos de la burocracia educativa son puestos que "pertenecen" al SNTE. Es a la luz de esta estructuración, formal e informal, que deben verse las posibilidades de que el director aplique de manera autónoma las infracciones referidas en el párrafo anterior.

2. El esfuerzo y calidad del trabajo docente, si se juzgan por las sanciones contempladas por su incumplimiento, son poco relevantes. El art. 39 señala que "la intensidad del trabajo estará determinada por el conjunto de labores que se asignen a cada empleo en los reglamentos interiores de las Dependencias de la Secretaría”. Hay que precisar que la elaboración de reglamentos corresponde a funcionarios y al sindicato.

Además, no recibe tratamiento especial (véase Cuadro 3) no "desempeñar las funciones propias de la docencia con la intensidad y calidad que ésta requiera" (art. 77, fracción $\mathrm{V}$ ); se combina con responsabilidades de menor grado, como no actuar con discreción, no tratar con cortesía y diligencia al público, denigrar actos de gobierno y desobedecer la autoridad, no procurar la armonía gubernamental y no comunicar irregularidades. Las sanciones pueden ser extrañamientos, amonestaciones verbales y escritas o notas malas. 
Cuál se aplicará -esto es muy relevante- dependerá del “juicio del jefe de la dependencia”.

3. El art. 76 y los incisos del a al $e$ del art. 80 regulan la puntualidad. El art. 76 estipula, de manera general, que no asistir con puntualidad y cumplir con los controles que se establezcan para medirla (art. 25, fracción II) dará lugar a malas notas (art. 71, fracción II). Inclusive se puede llegar a perder el "derecho a percibir el salario correspondiente a los días de inasistencia que se consideren injustificados”. Los incisos del art. 80 desglosan los retardos. Sea suficiente mencionar que se establecen escalas en los retardos e infracciones.

De estas se empieza con malas notas, luego se pierde el derecho a percibir salario (son faltas injustificadas cuando el trabajador se presenta a sus labores transcurridos 30 minutos), se suspende labores y, finalmente, se solicita al Tribunal el cese. Es responsabilidad del director vigilar la puntualidad y asistencia del personal escolar, así como su desempeño.

4. El art. 78 regula algunas de las conductas de los trabajadores de la educación. Es el artículo del gobierno del nivel operativo del sistema educativo. No abordaremos cada una de las conductas (no) esperadas. Lo que sí se resalta son las infracciones que amerita su incumplimiento o inobservancia: extrañamientos y amonestaciones verbales y escritas. Estas infracciones pueden derivar en sanciones más serias, dependiendo de su gravedad o reincidencia.

$\mathrm{Si}$ estas últimas lo ameritan (no se especifican condiciones ni se ofrecen detalles), la Secretaría estará en condiciones de solicitar al Tribunal la terminación de los efectos de los nombramientos, la sanción más grave. $\mathrm{El}$ deóntico "permitan a la SEP" no la obliga, sólo la faculta. Pero para que esto se dé, la Secretaría tiene que disponer de amplia información reportada por directores de planteles. No se menciona, pero el flujo de la información tiene que ascender la jerarquía organizacional operativa.

5. Los únicos casos en que el cese no parece tener tropiezos son aquellos descritos por el art. 79. En estos casos, el trabajador, por iniciativa propia, pone un pie fuera del sistema educativo. El primero refiere al caso de renuncia. Si el trabajador deja el servicio sin que se le haya aceptado la renuncia y no haya entregado "expedientes, documentos, fondos y valores o bienes cuya atención, administración o guarda estén a su cuidado” será cesado.

El segundo refiere a nueva adscripción. Si el trabajador no se traslada "al lugar de nueva adscripción señalado por la Secretaría en un plazo no mayor de cinco días contados a partir de la fecha en que hubiere hecho entrega de los asuntos de su anterior cargo" será cesado. Sin perjuicio, obviamente, de la responsabilidad penal en que pudiere incurrir el trabajador. Ni este artículo ni otro del Reglamento ofrecen más detalles. 
6. Las faltas también conducen al cese. Aquí también las faltas han de reportarse al Departamento de Personal para que la sanción sea efectiva. Mencionábamos antes que es responsabilidad del director vigilar la asistencia del personal escolar. Puede ser costoso asumir que el director aplicará la norma sólo porque así se establece. Sobre todo si, como es el caso, no se definen con claridad las sanciones por incumplimiento del principal, puesto de base.

7. Supongamos que el director - contrario a lo dicho con anterioridadactúa autónomamente, otorga extrañamientos a quien, según su juicio, se lo merece. Los artículos 75 y 81 (véase Cuadro 4) debilitan el I1 en el art. 74 (véase Cuadro 2). La primera parte del art. 75 continúa con el tono punitivo del art. 74: "Las notas malas serán permanentes en el expediente del trabajador". Luego viene la oportunidad de redención con los componentes D3, I2 y A3 y el C4 del art. 81.

Su estructuración es sobria y vaga, en comparación con la (relativa) precisión que se hace de las infracciones. La condición C3 para compensar malas notas es la realización de "servicios extraordinarios, acciones meritorias o cualesquiera otros motivos que justifiquen tal recompensa”. Pero, ¿qué hace "extraordinario" a un servicio o "meritoria" una acción? ¿De acuerdo con quién? No hay claridad ni en los artículos ni en el resto del Reglamento.

En suma, en este punto resalta la configuración de dos hechos. El primero gira en torno al atributo, componente clave. El Reglamento asume, para efectos de aplicar infracciones, autonomía del director (y de los otros principales a nivel operativo). Sin esa intervención autónoma las infracciones no tienen efecto sancionador. Sin embargo, esos puestos son basificados. El segundo elemento que viene a configurar la situación de acción es la posibilidad de contrarrestar los efectos sancionadores con lo estipulado en los artículos 75 y 81 . En este último prevalece la ambigüedad y la falta de claridad en los enunciados institucionales.

\section{Carril rápido}

El capítulo XII del Reglamento y los capítulos VI y VII de la LFTSE son equivalentes. Estos tratan sobre la suspensión y el cese. La suspensión no significa el cese del trabajador (art. 45, LFTSE). Las causas de suspensión son similares para ambas normas. Para la LFTSE, "que el trabajador contraiga alguna enfermedad que implique un peligro para las personas que trabajan con él" (fracción I); "La prisión preventiva [...], seguida de sentencia absolutoria o el arresto impuesto por autoridad judicial o administrativa, a menos que, tratándose de arresto el Tribunal [...] resuelva que debe tener lugar el cese”. 
Y, por último: "Los trabajadores que tengan encomendado manejo de fondos, valores o bienes, podrán ser suspendidos hasta por sesenta días por el titular de la dependencia respectiva, cuando apareciere alguna irregularidad en su gestión mientras se practica la investigación y se resuelve sobre su cese”. El deóntico "podrán” sólo autoriza, reflejando el tono distintivo de la normatividad.

Ningún trabajador de base puede ser cesado sino por causa justa. Así empieza el art. 46 de la LFTSE. Luego se enumeran las causas justas, cada fracción representando un tipo de ellas. Una de las causas de la fracción I -el abandono- es elaborada por el art. 60 del Reglamento. Las fracciones II, III y IV son claras para la ley, pues no ameritan mayor elaboración. Estas son las "puertas normales de escape" a las que se refería TB. No así las causas de la fracción V. Por la forma en que está redactado el enunciado institucional, la Secretaría tiene que solicitar primero -y no después- al Tribunal una resolución por las causas de los incisos. Las causas de los incisos son clasificadas como graves y no graves. Esto quiere decir que son requeridos diferentes cursos de acción, los cuales veremos enseguida.

El Cuadro 5 contiene los cursos de acción a seguir cuando se presentan dichas causas. El Reglamento, comparado con la LFTSE, es más antiguo y primitivo, escueto en detalles. Por eso se analiza primero. Al tratarse de las causas de la fracción V, el art. 59 ordena a la Secretaría a que invariablemente presente demanda ante el Tribunal de Arbitraje para cesar al trabajador. El enunciado de este artículo es contundente. Además, deja en claro que la Secretaría no está autorizada para cesar a ningún trabajador. Mientras que la demanda sigue en curso, la fracción III del art. 58 ordena a la Secretaría a que, "previa e invariablemente", pida permiso al sindicato para suspender al trabajador. El otro enunciado obliga al sindicato a dar permiso a la SEP cuando esta demuestre "que los hechos imputados al trabajador son de los comprendidos en la mencionada fracción” (C2). Lo único, pues, que la SEP puede, y tiene que hacer, es demandar y pedir permiso.

El lenguaje de la LFTSE adopta un tono menos tajante. Esto se ve en el uso de deónticos. Los cursos de acción, además, no se limitan a la suspensión y al cese, como en el Reglamento. Se agrega la opción de reubicar al trabajador. Así, la configuración organizacional se vuelve laxa y débil al momento de imponer consecuencias. También se incorporan diversos actores en la toma de decisiones.

La C7 del art. 46 Bis establece que ante cualquier causa enumerada en la fracción $\mathrm{V}$ se procederá a levantar acta administrativa. Por obvias razones, corresponde al principal o "jefe superior de la oficina", personal de 
base después de todo, levantarla. El deóntico implícito (D4) es inequívoco: "procederá a levantar". Para que el acta pueda ser usada posteriormente como "instrumento base de la acción" se requiere que la firmen varios: el sancionado, el jefe de la oficina, el representante sindical, testigos de cargo, de descargo y dos testigos de asistencia.

El acta administrativa es la única acción obligatoria que impone este enunciado. El último párrafo del art. 46 Bis introduce la condición C8 que contraviene o, al menos, neutraliza el mandato perentorio del art. 59 del Reglamento: "Si a juicio del Titular procede demandar", se demanda. Ya no es obligatorio como en el Reglamento. Independientemente de si la causa es grave o no, el titular de la dependencia "podrá suspender los efectos del nombramiento". Pero el diablo del corporativismo mete la cola inclusive en propósito tan débil como el I2 ("suspender") y para nivel tan alto en la organización como el del titular de la dependencia (A2). El mismo párrafo introduce la condición C4, improbable que se cumpla: "si con ello está conforme el Sindicato correspondiente". Aquí se bifurcan los cursos de acción dependiendo de si las causas son graves o no.

El titular tiene un recurso a la mano en caso de que el sindicato niegue permiso para suspender. Aparte de la condición C4, aquí aparece otra condición (C5) para ejercer dicho recurso: "cuando se trate de alguna de las causas graves previstas en los incisos a), c), e), y h)"; esto es, cuando las causas afectan la gobernabilidad y el orden de planteles escolares. En esos casos, el "titular podrá demandar la conclusión de los efectos del nombramiento", esté o no de acuerdo el sindicato. Si se lee el deóntico de manera literal, el titular sólo está autorizado para actuar, no está obligado, incluso en casos graves. Continúa el enunciado: el Tribunal "proveerá de plano, en incidente por separado la suspensión [...] sin perjuicio de continuar el procedimiento en lo principal hasta agotarlo en los términos y plazos que correspondan, para determinar en definitiva sobre la procedencia o improcedencia de la terminación de los efectos del nombramiento".

Sobre las causas no graves (incisos: $b, \mathrm{~d}, \mathrm{f}, \mathrm{g}$, i y j) no queda claro el curso de acción a seguir en términos de este enunciado institucional. El primer párrafo del art. 46, creemos, ofrece una salida tanto a las causas graves como a las no graves. Este enunciado autoriza (D1: "podrá") al jefe superior (i.e., director) ordenar la remoción del trabajador "a oficina distinta de aquella en que estuviera prestando sus servicios, dentro de la misma Entidad Federativa [...] hasta que sea resuelto en definitiva el conflicto por el Tribunal Federal de Conciliación y Arbitraje". Pero, debe agregarse, si procede la demanda, la

9 Las cursivas son nuestras. 
cual, como ya vimos, depende del juicio del titular y de que le llegue el informe de los hechos adecuado.

El componente clave de los enunciados analizados aquí es el deóntico, operador que indica si una acción es requerida, permitida o prohibida. El deóntico "podrá" de la LFTSE - novedoso en relación con el Reglamento- es a-direccional: ni prohíbe ni obliga. Abre espacio para que otros elementos se incorporen en la fórmula decisoria. Se crea un marco discrecional para que los actores promuevan o no la acción-propósito referido, dependiendo de criterios no-normativos. Debe precisarse, además, que, al tratarse de un movimiento que conduce al cese, es el "titular de la dependencia" el que tiene que tomar la decisión, lo cual refuerza el marco discrecional.

La SEP, pues, no puede cesar a trabajador de base alguno. Sólo puede suspenderlo temporalmente, siempre y cuando el sindicato esté de acuerdo. Lo único que puede hacer el "jefe superior de la oficina” es ordenar la remoción del trabajador a una oficina distinta. En suma, el abanico de sanciones se ensancha, diluyéndose. Con el deóntico "puede", se le quita el carácter determinante a los cursos de acción.

\section{Discusión y conclusiones}

Este trabajo muestra cómo la normatividad laboral, repositorio de reglas del juego para el caso de México, estructura problemas de agencia. Esta investigación contribuye al campo del análisis institucional de la educación básica. Con el bagaje teórico de la TA y la metodología de la IGT se mostró que la LFTSE y el Reglamento, herederos del Estatuto, configuran, en lugar de resolver, problemas de agencia en la educación básica.

La observación de TB de que el Estatuto no tenía "más puertas normales de escape que la renuncia, el retiro o la defunción”, personifica situaciones de riesgo moral en doble sentido. Problematiza lo limitado de la cantidad de "puertas de escape" o de salida y, además, señala la ausencia de mecanismos "normales" que, debiéndose activar, no se activan. Esto sucede así porque el mismo Estatuto permite la formación de coaliciones entre supervisores (principales) y maestros (agentes), facilitando la colusión. Luego la asimetría de información, la cual se traduce en pérdida de control para la SEP.

Se mostró que la seguridad laboral trepa la zona organizacional del personal operativo. El personal en puestos de función de principal (subdirectores, directores, supervisores, etcétera) era, al igual que maestros, personal basificado. Esto quiere decir que también era personal sindicalizado. ¿Se traduce ese hecho en formación de coaliciones? Al ser este un fenómeno conductual, 
la normatividad no puede detectarlo. TB observaba que sí. Atribuye a inspectores (o supervisores) racionalidad al momento de ejercer sus funciones. Los inspectores, por conveniencia, se inclinan por mostrar lealtad al sindicato vis a vis la autoridad educativa. Esta lealtad tiene su base material.

Muñoz-Armenta (2008: 399) nos recuerda que el SNTE, para el periodo que comprende este estudio, controlaba los mecanismos para "otorgar incentivos en forma de castigos y recompensas al conjunto de los trabajadores de la educación". Este control hace posible la formación de coaliciones tuteladas por el sindicato, en la que prevalezca la lógica sindical y laboral, como ya se vio con anterioridad (Gómez-Nashiki 2010; Ezpeleta y Weiss, 1994).

Ostrom (2009: 15) nos recuerda que la simple aprobación de una ley no equivale a crear una institución efectiva. El diseño es clave para entender el nivel de efectividad. La autora señala que "las reglas formales que alguien no supervisa y hace cumplir -los participantes, los funcionarios o ambos- son ineficaces y no modifican el comportamiento".

Por el otro lado, está claro que la LFTSE y el Reglamento contemplan procedimientos para aplicar sanciones. Después de todo, ese es su objeto. Sin embargo, al diseccionar la normatividad se constató que los procedimientos para aplicar sanciones, de supervisión, suponen que las figuras con puestos de principal a nivel operativo actuarían de manera autónoma, con apego a normas. La ventaja de hacer un análisis institucional con la IGT es que permite yuxtaponer, en diversos planos, distintos arreglos institucionales interactuantes. Así, el supuesto de autonomía del principal en la aplicación de sanciones coexiste, contradictoriamente, con la posible colusión de agentes y supervisores.

Otra consideración proviene de la deontología de la LFTSE, pieza que regula las sanciones fuertes. Para la aplicación de estas sanciones, se parte igualmente del supuesto previo: estas sólo son posibles con la actuación inicial y autónoma de la autoridad del plantel. No sólo eso. La LFTSE contempla, antes de llegar al cese, otras opciones en las sanciones. Aparte, se enfatiza el "criterio" del titular de la dependencia para poner en marcha las sanciones.

Los deónticos, en última instancia, sólo facultan a los actores involucrados para llevar a cabo cualquier tipo de sanción. Esta estructuración le puede quitar estrés a la gobernanza del sistema educativo. También está la otra cara de la moneda: se crea una zona discrecional para el juego político en los actores preponderantes del sistema educativo: los representantes de gobierno y el sindicato de maestros. Históricamente, esta opción ha sido muy socorrida. Las sanciones, pues, están sujetas a las negociaciones políticas al interior del sistema educativo. 
El presente trabajo tiene algunas limitaciones. Primero, las piezas normativas analizadas son sólo la LFTSE y el Reglamento. El corpus normativo que regula la conducta de los maestros o que puede influirla es mucho más amplio. Además, las reglas del juego no son sólo formales. También están las reglas o normas informales que afectan la conducta de los maestros. Estudios futuros podrían ampliar el enfoque. La perspectiva teórica que se utilizó, la TA, usa conceptos (problemas de agencia, riesgo moral, etc.) que no son familiares en estudios hispanoparlantes.

Asimismo, pudiera haber sesgo en los supuestos de esta teoría sobre la naturaleza de los actores, maestros en este caso: maximizadores de utilidades proclives a incurrir en prácticas oportunistas. Hay que tener presente, no obstante, que las observaciones de TB sobre la conducta docente colocaron en esta dirección la discusión. Metodológicamente, también hay espacio para la mejora. Estudios futuros habrán de considerar cuestiones de confiabilidad en el análisis al incorporar métodos más robustos.

En conclusión, aparte de la renuncia, el retiro o la defunción, había pocas posibilidades para que un maestro perdiera su empleo o se le sancionara seriamente. Para que sucediera, era preciso que se dieran los supuestos mencionados. Sería enriquecedor que estudios futuros retomaran esta discusión para analizar la dimensión conductual de los maestros.

Este trabajo trata sobre los arreglos institucionales que emergieron alrededor de 1940. A partir del año 2012, con el retorno del PRI al Poder Ejecutivo federal, se ha implementado una reforma derivada del llamado Pacto por México, que posiblemente modifique los arreglos mencionados. Investigaciones posteriores podrían retomar la perspectiva de este estudio para hacer un balance sobre los cambios hechos en términos de los problemas de agencia.

\section{Referencias}

Arnott, Richard y Stiglitz, Joseph (1991), "Moral Hazard and Nonmarket Institutions: Dysfunctional Crowding Out of Peer Monitoring?", en The American Economic Review, vol. 81, núm. 1, Estados Unidos: Columbia University Academic Commons. DOI: $10.7916 / \mathrm{D} 8 \mathrm{NV} 9 \mathrm{~V} 7 \mathrm{~F}$.

Basurto, Xavier et al. (2009), "A Systematic Approach to Institutional Analysis: Applying Crawford and Ostrom's Grammar”, en Political Research Quarterly, vol. 63, núm. 3, Estados Unidos: Sage. DOI: 10.1177/106591290933443

Bracho, Teresa, y Zorrilla, Margarita (2015), "Perspectiva de un gran reto", en INEE, Reforma Educativa: Marco Normativo, México: Instituto Nacional para la Evaluación de la Educación. Disponible en: http://www.inee.edu.mx/index.php/servicioprofesional-docente/517-reforma-educativa/marco-normativo/1607-marconormativo [6 de junio de 2017]. 
Calvo-Pontón, Beatriz et al. (2002), La supervisión escolar de la educación primaria en México: prácticas, desafíos y reformas, Francia: Instituto Internacional de Planeamiento de la Educación. Disponible en: http://unesdoc.unesco.org/ images/0012/001261/126190so.pdf [20 de enero de 2017].

Casson, Michael (2007), "Reducing Teacher Moral Hazard in the U.S. Elementary and Secondary Educational System through Merit-pay: An Application of the PrincipalAgency Theory”, en Social Economics, vol. 36, núm. 2, Países Bajos: Springer. DOI: 10.1007/s12143-007-9004-3.

Crawford, Sue y Ostrom, Elinor (1995), “A Grammar of Institutions”, en The American Political Science Review, vol. 89, núm. 3, Estados Unidos: Cambridge University Press. DOI: $10.2307 / 2082975$.

Davis, Lance y North, Douglass (1971), Institutional Change and American Economic Growth, Estados Unidos: Cambridge University Press.

Ezpeleta, Justa (1997), “Algunos desafíos para la gestión de las escuelas multigrado”, en Revista Iberoamericana de Educación, núm. 15, México: Organización de Estados Iberoamericanos para la Educación, la Ciencia y la Cultura. Disponible en: https:// dialnet.unirioja.es/servlet/articulo?codigo=1020263 [ 12 de junio de 2016].

Ezpeleta, Justa (1990), "El consejo técnico: eficacia pedagógica y estructura de poder en la escuela primaria mexicana”, en Revista Latinoamericana de Estudios Educativos, vol. XX, núm. 4, México: Centro de Estudios Educativos. Disponible en: http://www.cee. edu.mx/revista/r1981_1990/r_texto/t_1990_4_02.pdf [12 de junio de 2016].

Ezpeleta, Justa (2004a), "Innovaciones Educativas: Reflexiones sobre los Contextos en su Implementación”, en Revista Mexicana de Investigación Educativa, vol. 9, núm. 21, México: Consejo Mexicano de Investigación Educativa. Disponible en: http://www. comie.org. $\mathrm{mx} / \mathrm{v} 1 /$ revista/portal.php?idm $=$ es\&sec $=S C 03 \&$ sub $=S B B \&$ criterio $=A$ RT00420 [12 de junio de 2016].

Ezpeleta, Justa (2004b), "Lo institucional de la escuela en las políticas de reforma educativa”, en Tenti-Fanfani, Emilio [coord.], Gobernabilidad de los sistemas educativos en América Latina, Francia: Instituto Internacional de Planeamiento de la Educación-Unesco. Disponible en: http://unesdoc.unesco.org/images/0014/001443/144336s.pdf [12 de junio de 2016].

Ezpeleta, Justa (1992), “Problemas y teoría a propósito de la gestión pedagógica”, en Ezpeleta, Justa y Furlán, Alfredo [comps.], La gestión pedagógica de la escuela, Chile: Unesco-Oficina Regional de Educación. Disponible en: http://unesdoc.unesco.org/ images/0009/000919/091936SB.pdf [12 de junio de 2016].

Ezpeleta,JustayFurlán,Alfredo(1992), “Prólogo”,enEzpeleta,JustayFurlán,Alfredo[comps.], La gestión pedagógica de la escuela, Chile: Unesco-Oficina Regional de Educación. Disponible en: http://unesdoc.unesco.org/images/0009/000919/091936SB.pdf [12 de junio de 2016].

Ezpeleta, Justa y Weiss, Eduardo (1994), "La precariedad institucional de las escuelas: de la imagen a las políticas", en Ezpeleta, Justa y Weiss, Eduardo [comps.], Programa para Abatir el Rezago Educativo: Evaluación Cualitativa del Impacto. Informe Final, México: Departamento de Investigaciones Educativas-Centro de Investigación y de Estudios Avanzados del Instituto Politécnico Nacional.

Ezpeleta, Justa y Weiss, Eduardo (1996), "Las escuelas rurales en zonas de pobreza y sus maestros: tramas preexistentes y políticas innovadoras", en Revista Mexicana de 
Convergencia Revista de Ciencias Sociales, núm. 77, 2018, Universidad Autónoma del Estado de México

Investigación Educativa, vol. 1, núm. 1, México: Consejo Mexicano de Investigación Educativa. Disponible en: http://www.comie.org.mx/v1/revista/portal.php?idm=es $\&$ sec $=S C 03 \&$ sub $=S B B \&$ criterio $=A R T 00180$ [12 de junio de 2016].

Ferris, James (1992), "School-Based Decision Making: A Principal-Agent Perspective”, en Educational Evaluation and Policy Analysis, vol. 14, núm. 4, Estados Unidos: Sage. DOI: $10.3102 / 01623737014004333$.

Gibson, Clark et al. (2005), The Samaritan's Dilemma: The Political Economy of Development Aid, Estados Unidos: Oxford University Press.

Gómez-Nashiki, Antonio (2010), "Micropolítica escolar y procesos de cambio: el papel del supervisor en una institución educativa”, en Revista Mexicana de Investigación Educativa, vol. 15, núm. 46, México: Consejo Mexicano de Investigación Educativa. Disponible en: http://www.comie.org.mx/v1/revista/portal.php?idm=es\&sec=SC0 3\&sub $=$ SBB\&criterio $=$ ART 46004 [22 de junio de 2016].

Jensen, Michael y Meckling, William (1976), “Theory of the Firm: Managerial Behavior, Agency Costs, and Ownership Structure”, en Journal of Financial Economics, vol. 3, núm. 4, Estados Unidos: Elsevier. DOI: 10.1016/0304-405X(76)90026-X.

Kiser, Larry y Ostrom, Elinor (1982), “The Three Worlds of Action: A Metatheoretical Synthesis of Institutional Approaches", en Ostrom, Elinor [ed.], Strategies of Political Inquiry, Estados Unidos: Sage.

Knoepfel, P. et al. (2007), Public Policy Analysis, Reino Unido: The Policy Press.

Lane, Jan (2008), Comparative Politics. The Principal-agent Perspective, Estados Unidos: Routledge.

Lane, Jan y Svante, Ersson (2000), The New Institutional Politics: Performance and Outcomes, Estados Unidos: Routledge.

Levaćič, Rosalind (2009), "Teacher Incentives and Performance: An Application of Principal-Agent Theory”, en Oxford Development Studies, vol. 37, núm. 1, Reino Unido: Taylor \& Francis. DOI: 10.1080/13600810802660844.

Loyo-Brambila, Aurora (2010), "Política educativa y actores sociales", en Arnaut, Alberto y Giorguli, Silvia [coords.], Los grandes problemas de México, vol. VII, México: El Colegio de México. Disponible en: http://2010.colmex.mx/tomos/educacion 1.html [24 de agosto de 2015].

Moe, Terry (2005), "Political Control and the Power of the Agent", en The Journal of Law, Economics \& Organization, vol. 22, núm. 1, Estados Unidos: Oxford. DOI: 10.1093/ jleo/ewj011.

Moe, Terry (1984), "The New Economics of Organization”, en American Journal of Political Science, vol. 28, núm. 4, Estados Unidos: Midwest Political Association. DOI: $10.2307 / 2110997$.

Muñoz-Armenta, Aldo (2008), "Escenarios e identidades del SNTE: entre el sistema educativo y el sistema político", en Revista Mexicana de Investigación Educativa, vol. 13, núm. 37, México: Consejo Mexicano de Investigación Educativa. Disponible en: https://www.comie.org.mx/v1/revista/portal.php?idm=es\&sec=SC03\&sub=SBB\& criterio $=$ ART37002 [8 de agosto de 2015].

North, Douglass (1993), Instituciones, cambio institucional y desempeño económico, México: Fondo de Cultura Económica.

Ornelas, Carlos (2002), "Incentivos a los maestros: la paradoja mexicana", en Ornelas, Carlos [comp.], Valores, calidad y educación, México: Santillana-Aula XXI. 
Ornelas, Carlos (2008), Politica, poder y pupitres: critica al nuevo federalismo educativo, México: Siglo XXI.

Ostrom, Elinor (2007), "Institutional Rational Choice: An Assessment of the Institutional Analysis and Development Framework", en Sabatier, Paul [ed.], Theories of the Policy Process, Estados Unidos: Westview Press.

Ostrom, Elinor (2005), Understanding Institutional Diversity, Estados Unidos: Princeton University Press.

Ostrom, Elinor y Basurto, Xavier (2010), “Crafting Analytical Tools to Study Institutional Change”, en Journal of Institutional Economics, vol. 7, núm. 3, Reino Unido: Cambridge University Press. DOI: 10.1017/S1744137410000305.

Otrom, Elinor (2009), "Las reglas que no se hace cumplir son pura palabrería”, en Revista de Economia Internacional, vol. II, Colombia: Universidad Externado de Colombia. Disponible en: https://www.economiainstitucional.com/pdf/No21/eostrom21.pdf [15 de mayo de 2017].

Rauchhaus, Robert (2009), "Principal-Agent Problems in Humanitarian Intervention: Moral Hazards, AdverseSelection and the Commitment Dilemma”, en International Studies Quarterly, vol. 53, núm. 4, Estados Unidos: Wiley. DOI: 10.1111/j.14682478.2009.00560.x.

Shapiro, Susan (2005), "Agency Theory", en Annual Review of Sociology, vol. 31, núm. 1, Estados Unidos: American Bar Foundation. DOI: 10.1146/annurev. soc.31.041304.122159.

Siddiki, Saba et al. (2011), "Dissecting Policy Designs: An Application of the Institutional Grammar Tool”, en The Policy Studies Journal, vol. 39, núm. 1, Estados Unidos: Wiley. DOI: $10.1111 /$ j.1541-0072.2010.00397.x.

Street, Susan (1983), "Burocracia y educación: hacia un análisis político de la desconcentración administrativa en la Secretaría de Educación Pública (SEP)”, en Estudios Sociológicos, vol. 1, núm. 2, México: El Colegio de México. Disponible en: http://estudiossociologicos.colmex.mx/index.php/es/article/view/1297 [8 de agosto de 2015].

Tapia-Uribe, Medardo (2004), "Federalización y gestión educativa estatal: el caso de Morelos", en Revista Mexicana de Investigación Educativa, vol. 9, núm. 21, México: Consejo Mexicano de Investigación Educativa. Disponible en: http://www.comie.org. $\mathrm{mx} / \mathrm{v} 1 /$ revista/portal.php?idm $=$ es\&sec $=$ SC03\&sub=SBB\&criterio=ART00419 [8 de agosto de 2015].

Tirole, Jean (1986), "Hierarchies and Bureaucracies: On the Role of Collusion in Organizations", en Journal of Law, Economics \& Organization, vol. 2, núm. 2, Reino Unido: Oxford. DOI: 10.1093/oxfordjournals.jleo.a036907.

Torres-Bodet, Jaime (1994), Textos sobre educación, México: Consejo Nacional para la Cultura y las Artes. 


\section{Anexo}

\section{Cuadro 1}

Ejemplo ficticio de un enunciado institucional codificado: El alumno entregará avances sustanciales de su tesis según fechas estipuladas en el calendario escolar de la Universidad $\mathrm{X}$ o será dado de baja de manera puntual

\begin{tabular}{|c|c|c|}
\hline $\begin{array}{l}\text { Componente } \\
\text { (ABDICO) }\end{array}$ & Definición de componente & $\begin{array}{l}\text { Codificación de un ejemplo } \\
\text { de enunciado }\end{array}$ \\
\hline Atributo & $\begin{array}{l}\text { Agentes encargados de llevar a } \\
\text { cabo una acción particular }\end{array}$ & "El alumno..." \\
\hline propósIto & Acción & “... entregará ...” \\
\hline oBjeto & $\begin{array}{l}\text { Parte animada o inanimada del } \\
\text { enunciado receptor de una acción }\end{array}$ & $\begin{array}{l}\text { "... avances sustanciales de } \\
\text { tesis..." }\end{array}$ \\
\hline $\begin{array}{l}\text { Condiciones } \\
\text { (Estrategia) }\end{array}$ & $\begin{array}{l}\text { Límites espaciales, temporales } \\
\text { y/o procesuales en los cuales se } \\
\text { lleva a cabo una acción }\end{array}$ & $\begin{array}{l}\text { “... según fechas estipuladas } \\
\text { en el calendario escolar oficial } \\
\text { de la Universidad X” }\end{array}$ \\
\hline $\begin{array}{l}\text { Deóntico } \\
\text { (Norma) }\end{array}$ & $\begin{array}{l}\text { Operador que especifica si una } \\
\text { acción es requerida, permitida o } \\
\text { prohibida }\end{array}$ & “... (tiene que, implícito)...” \\
\hline $\begin{array}{l}\text { De lo ContrariO } \\
\text { (Regla) }\end{array}$ & $\begin{array}{l}\text { Sanción punitiva asociada con no } \\
\text { llevar a cabo una acción como fue } \\
\text { prescrita }\end{array}$ & $\begin{array}{l}\text { “... o será dado de baja de } \\
\text { manera puntual". }\end{array}$ \\
\hline
\end{tabular}

Fuente: Elaborada a partir de Crawford y Ostrom (1995), Basurto et al. (2009) y Siddiki et al. (2011).

\section{Cuadro 2}

\section{Sintaxis gramatical del Reglamento, notas malas}

Art. 74. ${ }^{\mathrm{C} 1}$ Previa justificación, ${ }^{\mathrm{B} 1}$ las notas malas ${ }^{\mathrm{D} 1}$ serán ${ }^{\mathrm{I1}}$ impuestas por ${ }^{\mathrm{A} 1}$ el Departamento de Personal con notificación al afectado, ${ }^{\mathrm{C} 2}$ y a solicitud, en su caso, ${ }^{\mathrm{A} 2}$ de la dependencia donde preste sus servicios el trabajador.

Fuente: Elaboración propia. 


\section{Cuadro 3}

\section{Sintaxis gramatical del Reglamento (editada), infracciones varias}

Art. 76. La falta de cumplimiento a la fracción II del artículo 25 dará lugar a la aplicación de lo dispuesto por la fracción II del artículo 71 (notas malas en la hoja de servicio), sin perjuicio de la pérdida de derecho a percibir el salario correspondiente a los días de inasistencia, que se considerarán injustificados.

Art. 77. La falta de cumplimiento a las obligaciones que señalan las fracciones V, VII, VIII, X, XV y XVI del artículo 25, dará lugar a la aplicación de las fracciones I (extrañamientos y amonestaciones verbales y escritas) y II (notas malas en la hoja de servicio) del artículo 71 en su caso, a juicio del jefe de la dependencia donde preste sus servicios el trabajador.

Art. 78. La falta de cumplimiento de las obligaciones marcados por las fracciones VI, IX, XII y XIV del artículo 25, y la inobservancia de las prevenciones enumeradas en el artículo 26, dará lugar a la aplicación de la fracción I del artículo 71 (Extrañamientos y amonestaciones verbales y escritas), sin perjuicio de que la gravedad de estas infracciones o la reincidencia, en su caso, permitan a la (SEP) solicitar del Tribunal de Arbitraje la terminación de los efectos de los nombramientos respectivos.

Art. 79. La falta de cumplimiento a los incisos XI y XIII del artículo 25 dará lugar a la aplicación del artículo 71 de este Reglamento (cese de los efectos del nombramiento), sin perjuicio de la responsabilidad penal en que pudiere incurrir el trabajador.

Fuente: Elaboración propia.

\section{Cuadro 4}

\section{Sintaxis gramatical del Reglamento, compensación de notas malas}

Art. 75. ${ }^{\mathrm{B} 2}$ Las notas malas ${ }^{\mathrm{D} 2}$ serán permanentes en el expediente del trabajador $\mathrm{y}^{\mathrm{D} 3}$ podrán ${ }^{\mathrm{I} 2}$ ser compensadas con notas a que se haga ${ }^{\mathrm{A} 3}$ acreedor ${ }^{\mathrm{C} 3}$ por servicios extraordinarios, acciones meritorias o cualesquiera otros motivos que justifiquen tal recompensa.

Art. 81. ${ }^{\mathrm{A} 4}$ Los trabajadores al servicio de la Secretaría ${ }^{\mathrm{D} 4}$ tendrán derecho ${ }^{\mathrm{B} 4}$ a recompensas ${ }^{\mathrm{C} 4}$ por los servicios meritorios que presten en el desempeño de sus funciones y que ${ }^{\mathrm{D} 5}$ podrán ${ }^{\mathrm{I} 3}$ consistir en: ${ }^{\mathrm{B} 5}$ a) Notas buenas en su hoja de servicios; y b) Felicitaciones por escrito.

Fuente: Elaboración propia. 


\section{Cuadro 5}

\section{Enunciados institucionales de causales de suspensión y cese, LFTSE y Reglamento}

\section{LFTSE}

\section{Art. 46. (Continuación)}

${ }^{\mathrm{C} 1}$ En los casos a que se refiere (la) fracción (V), ${ }^{\mathrm{A} 1}$ el Jefe superior de la oficina respectiva ${ }^{D 1}$ podrá ${ }^{11}$ ordenar ${ }^{B 1}$ la remoción del trabajador que diere motivo a la terminación de los efectos de su nombramiento, a oficina distinta de aquella en que estuviere prestando sus servicios, dentro de la misma Entidad Federativa ${ }^{\mathrm{C} 2}$ cuando esto sea posible, hasta que sea resuelto en definitiva el conflicto por el Tribunal Federal de Conciliación y Arbitraje.

${ }^{\mathrm{C} 3}$ Por cualquiera de las causas a que se refiere (la) fracción (V), ${ }^{\mathrm{A} 2}$ el titular de la Dependencia ${ }^{\mathrm{D} 2}$ podrá ${ }^{\mathrm{I} 2}$ suspender ${ }^{\mathrm{B} 2}$ los efectos del nombramiento ${ }^{\mathrm{C} 4}$ si con ello está conforme el Sindicato correspondiente; ${ }^{\mathrm{C} 5}$ pero si éste no estuviere de acuerdo, ${ }^{\mathrm{C} 6} \mathrm{y}$ cuando se trate de alguna de las causas graves previstas en los incisos a), c), e), y h), ${ }^{\mathrm{A} 3}$ el Titular ${ }^{\mathrm{D} 3}$ podrá ${ }^{13}$ demandar ${ }^{\mathrm{B} 3}$ la conclusión de los efectos del nombramiento, ante el Tribunal Federal de Conciliación y Arbitraje, el cual proveerá de plano, en incidente por separado, la suspensión de los efectos del nombramiento, sin perjuicio de continuar el procedimiento en lo principal hasta agotarlo en los términos y plazos que correspondan, para determinar en definitiva sobre la procedencia o improcedencia de la terminación de los efectos del nombramiento.

Cuando el Tribunal resuelva...

Art. 46 Bis: ${ }^{\mathrm{C} 7} \mathrm{Cuando}$ el trabajador incurra en alguna de las causales a que se refiere la fracción $\mathrm{V}$ del artículo anterior, ${ }^{\mathrm{A} 4}$ el jefe superior de la oficina ${ }^{\mathrm{I}, \mathrm{D} 4}$ procederá a levantar ${ }^{\mathrm{B} 4}$ acta administrativa, con intervención del trabajador y un representante del Sindicato respectivo, en la que con toda precisión se asentarán los hechos, la declaración del trabajador afectado y las de los testigos de cargo y de descargo que se propongan, la que se firmará por los que en ella intervengan y por dos testigos de asistencia, debiendo entregarse en ese mismo acto una copia al trabajador y otra al representante sindical.

${ }^{\mathrm{C} 8} \mathrm{Si}$ a juicio del ${ }^{\mathrm{A} 5}$ Titular ${ }^{15}$ procede demandar ante el Tribunal Federal de Conciliación y Arbitraje la terminación de los efectos del nombramiento del trabajador, a la demanda

${ }^{16}$ se acompañarán, como instrumentos base de la acción, el acta administrativa y los documentos que, al formularse ésta, se hayan agregado a la misma.

10 Se refiere al art. 45 de la LFTSE. El Estatuto fue derogado.

11 Se refiere al art. 46 de la LFTSE. El Estatuto fue derogado. 
Reglamento

Art. 58. La suspensión de los efectos del nombramiento de los trabajadores a que se refiere el artículo 431 del Estatuto, sin perjuicio de lo que dispone la Ley de Responsabilidades de Funcionarios y Empleados de la Federación, se decretará de acuerdo con las siguientes reglas:

I...

II...

III. ${ }^{\mathrm{C} 1}$ En los casos de suspensión a que se refiere la fracción V del artículo 44 del estatuto2, ${ }^{A 1}$ la Secretaría, ${ }^{D 1}$ previa e invariablemente ${ }^{\mathrm{I} 1}$ solicitará ${ }^{\mathrm{B} 1}$ del Sindicato su conformidad con tal suspensión, $\mathrm{y}^{\mathrm{A} 2}$ éste a su vez ${ }^{\mathrm{D} 2}$ estará obligado ${ }^{\mathrm{I} 2 \mathrm{~B} 2}$ a otorgarla ${ }^{\mathrm{C} 2}$ si aquélla demuestra que los hechos imputados al trabajador son de los comprendidos en la mencionada fracción.

Art. 59. ${ }^{\mathrm{C} 3}$ En la aplicación de la fracción V del artículo 44 del estatuto, ${ }^{\mathrm{A} 3}$ la Secretaría ${ }^{\mathrm{D} 3}$ deberá invariablemente ${ }^{\mathrm{I} 3}$ presentar ${ }^{\mathrm{B} 3}$ demanda ante el Tribunal de Arbitraje, pidiendo autorización para cesar al trabajador, sin responsabilidad para el Estado.

Fuente: Elaboración propia.

Reynaldo Angulo-Cázares. Doctor en Ciencias Sociales por El Colegio de Sonora, mexicano. Profesor-investigador en el Instituto de Investigaciones Sociales de la Universidad Autónoma de Baja California, Mexicali. Líneas de investigación: análisis institucional y de políticas en la educación básica en México. Publicación reciente: Angulo Cázares, Reynaldo, "Problemas de Agencia en la Normatividad Laboral de la Educación Básica en México”, en Roa Rivera, Reyna Isabel et al (ed.), Migración, Educación y Sociedad: Visiones y experiencias desde la frontera, Bogotá: Redlpe (2017).

Recepción: 14 de noviembre de 2017.

Aprobación: 28 de febrero de 2018. 
